GU J Sci, Part C, 7(1): 97-111 (2019)

Gazi Üniversitesi
Fen Bilimleri Dergisi
PART C: TASARIM VE TEKNOLOJI
http://dergipark.gov.tr/gujsc

\title{
Baraj Yıkılması Taşkın Dalgası Yayılımının 1-Boyutlu Sayısal Simülasyonlarla İncelenmesi: Rahmanlar Barajı Örneği
}

\author{
Nazlı PALAMUT KEMALOĞLU ${ }^{1}$, Müsteyde BADUNA KOÇYİĞİT ${ }^{2, *}$, Hüseyin AKAY²

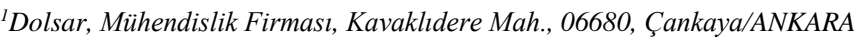 \\ ${ }^{2}$ Gazi Üniversitesi, Mühendislik Fakültesi, İnşaat Mühendisliği Bölümü, 06570, Çankaya/ANKARA
}

$\ddot{O} \mathbf{z}$

$\underline{\text { Makale Bilgisi }}$

Başvuru: $12 / 09 / 2018$

Düzeltme: 08/12/2018

Kabul: $10 / 01 / 2019$

\begin{tabular}{l} 
Anahtar Kelimeler \\
\hline Baraj yıkılması \\
HEC-RAS \\
Dalga yayılması \\
Rahmanlar Barajı
\end{tabular}

Keywords

Dam break HEC-RAS

Wave propagation Rahmanlar Dam
Baraj yıkılması sonucu oluşacak taşkın hareketinin belirlenmesi, baraj mansabında herhangi bir yerleşim yeri, ticari veya tarımsal alanların olması durumunda oluşabilecek tehlikenin saptanması açısından önemli ve gerekli bir çalışmadır. Günümüzde söz konusu çalışmalar için sayısal model simülasyonları yaygın olarak kullanılmaktadır. Bu çalışma kapsamında İzmir'in Ödemiş İlçesinde yapımı tamamlanmak üzere olan Rahmanlar Barajı'nın 1-Boyutlu (1B) yıkılma analizleri gerçekleştirilerek barajın yıkılması sonucu oluşacak taşkının mansapta yer alan üç adet köye ulaşıp ulaşamayacağı belirlenmiştir. Çalışmada 1B sayısal benzeşimleri için HEC-RAS (Hydrologic Engineering Center's River Analysis System) yazılımı kullanılmıştır. Taşkın alanları model sonuçlarına göre çizilmiş ve maksimum su yüzeyi yükseklikleri ile pik debilerin oluşma zamanları tespit edilmiştir. Yapılmış olan farklı yıkılma senaryolarına ait simülasyonlara göre 1B dinamik analizlerde akımın doğrusal bir şekilde ilerlemesi nedeniyle arazinin ve akımın fiziksel özelliklerinin istenilen doğrulukta tanımlanamadığı ve bu durumun sonuçları etkileyebildiği, ancak simülasyon süreleri göz önüne alındığında bir saat gibi bir sürede sonuçların elde edilebildiği görülmüştür. $\mathrm{Bu}$ nedenle Türkiye'de mevcut veya projelendirme aşamasında olan barajların mansap güvenliği ile ilgili çalışmalar yapılırken çalışmanın önem ve aciliyet durumuna göre öncelikle 1B yıkılma analizlerinin gerçekleştirilip sonuçlarının değerlendirilmesi, sonrasında öncelikle $2 \mathrm{~B}$ ve gerekli görülmesi halinde 3B analizlerin yapılması önerilmektedir.

\section{Investigation of 1-D Numerical Simulations of Dam Break Flood Wave Propagation: Case of Rahmanlar Dam}

\begin{abstract}
Determination of flood wave propagation occuring as a result of dam break is an important and essential study in determining risks on any residential, commercial or agricultural areas located in downstream regions of that dam. Today, numerical model simulations are widely used for such studies. Within the scope of this study, 1-Dimensional (1D) analysis of dam break of the Rahmanlar Dam, which is about to be completed in the Ödemiş District of İzmir was conducted to determine whether or not the flood wave occurred as a result of dam break would reach the three villages located at the downstream of the dam. In the study, the HEC-RAS (Hydrologic Engineering Center's River Analysis System) was used for 1D simulations. Flooded areas have been mapped according to the results of model analysis and the maximum water surface elevations and the time of occurrence of peak discharges have been determined. According to the simulations of different dam break scenarios, it was noted that the physical properties of land and stream flow could not be identified with desired accuracy in the model due to the unidirectional flow propagation in 1D dynamic analysis and this might affect the results of the model. However, when the computational time of the model analysis was taken into account, it was found that the analysis were completed in a short period of time like one hour or so. Therefore, 1-D analysis should be carried out for safety analysis of the downstream regions of any dam in Turkey either in operation or design stage depending on the importance and urgency of the study. After evaluation of those results, it is recommended to perform 2-Dimensional analysis and, if necessary, 3-Dimensional analysis.
\end{abstract}




\section{GİRIŞ (INTRODUCTION)}

Barajlar, sulama ve içme suyu temini, elektrik üretimi gibi nedenlerle inşa edilen ve membannda önemli miktarlarda su depolayabilen yapılardır. Nadir olmakla birlikte meydana gelen baraj yıkılmaları mansaplarında neden oldukları katastrofik taşkınlar nedeniyle son derece yıkıcı olabilmekte, ciddi can ve mal kayıplarına yol açabilmektedir. Bu nedenlerle baraj yıkılması sonucunda oluşacak taşkın dalgası büyüklüğ̈̈ ve yayılımının incelenerek meydana gelebilecek zararın mümkün olduğunca azaltılması gerekmektedir.

Baraj yıkılması ve bunun sonucunda oluşacak taşkın dalgasının mansap bölgesinde yayılması ile ilgili arazi verisi elde etmekte çeşitli zorluklar söz konusudur. Bu nedenle literatürde sınırlı sayıda deneysel çalışma ile ağırlıklı olarak sayısal model çalışmaları bulunmaktadır. Bu çalışmalardaki ortak amaç taşkın dalgası yayılma hızı ve yüksekliği gibi parametreler ile bunlar üzerinde etkili olan faktörlerin belirlenmesidir. Deneysel çalışmalarda farklı taban eğimleri ve taşkın dalgasının zamanla değişimi $[1,2,3,4]$ ile ilgili çalışmalar veya tabanda farklı engellerin olması durumları gibi farklı konular incelenmiştir [5, 6, 7, 8, 9, 10, 11, 12,13].

Olası bütün baraj yıkılmalarını önlemek imkânsız olsa da yıkılmanın zararlarından kaçınmak mümkündür [14]. Bu, ancak baraj mansabındaki yerleşim alanlarına taşkın dalgası ulaşmadan erken tahliye ile başarılabilir. Bu tür afetlerin olumsuz etkilerini hafifletmek amaciyla, mevcut veriler yardımıyla sayısal ve fiziksel modellere dayalı acil eylem planları oluşturulabilir. Bu modellerin yardımıyla her baraj yıkılma olayının sel bilgisi ve taşkın dalgalarının yayılım zamanı tahmin edilerek elde edilen sonuçlar doğrultusunda acil yönetim rehberleri düzenlenebilir. Bu acil durum planları; taşkın haritalarını, her yerleşim sınırı için uyarı zaman tablolarını ve en önemlisi can kaybından korunmak için erken uyarı sisteminin kurulmasını kapsayabilir. Amerika Birleşik Devletleri'nde (ABD) 1970'li yıllarda görülen pek çok baraj yıkılma olayı önemli can ve mal kayıpları ile sonuçlanmıştır. ABD'de o tarihlerden günümüze baraj yıkılması olayları hakkında geniş araştırmalar ve çalışmalar yoğun bir şekilde devam etmektedir. Türkiye'de ise baraj yıkılma olaylarının potansiyel tehlikelerinin tahmini ve acil durum yönetimi için görevlilere işe yarar veri sağlayabilmek amacıyla baraj yıkılması olaylarının sayısal analizlerinin gerçekleştirilmesi yaygınlaşarak artmaktadır $[15,16,17]$.

Bu çalışmada, Türkiye'nin batısında İzmir İli'nin Ödemiş ilçesinde yer alan Rahmanlar Barajı'nın sayısal yıkılma analizlerinin yapıldığı, taşkın haritaları ile taşkın özelliklerinin belirlendiği ve mansapta bulunan yerleşim yerlerinin güvenliği ile ilgili değerlendirmenin yapıldığı Yüksek Lisans Tez çalışmasına ait sonuçlar sunulmaktadır [18]. Çalışmada sayısal analizler 1B HEC-RAS yazılımı kullanılarak gerçekleştirilmiştir.

\section{SAYISAL YÖNTEM (NUMERICAL METHOD)}

Çalışmada 1B analizler için ücretsiz olarak temin edilebilen HEC-RAS yazılımı kullanılmıştır. Bu modelle özellikle serbest yüzeyli akımlar için zamana bağlı ve zamandan bağımsız akım koşullarında tek yönlü olarak akarsuyun hidrolik/hidrodinamik analizleri yapılabilmektedir. Yıkılma sonucu oluşan taşkın dalgasının mansapta ötelenmesi ise zamanla değişen akım denklemleri kullanılarak yapılmaktadır. Model, süreklilik ve momentum korunumuna dayalı sığ akım denklemlerinin tek yönlü özel durumu olan Saint-Venant eşitliklerini içermektedir [19].

$$
\begin{aligned}
& \frac{\partial \mathrm{A}}{\partial \mathrm{t}}+\frac{\partial \mathrm{Q}}{\partial \mathrm{x}}=\mathrm{q} \\
& \mathrm{I}_{\mathrm{E}}=\mathrm{I}_{0}-\frac{\partial \mathrm{y}}{\partial \mathrm{x}}-\frac{\mathrm{v}}{\mathrm{g}} \frac{\partial \mathrm{v}}{\partial \mathrm{x}}-\frac{1}{\mathrm{~g}} \frac{\partial \mathrm{v}}{\partial \mathrm{t}}
\end{aligned}
$$

Burada $A=$ debinin geçtiği akım alanı; $Q=$ kesit alandan geçen toplam debi; $q=$ kanalın birim genişliğinden geçen debi; $v=$ kanal boyunca ortalama akım hızı; $x=$ kanal uzunluğu; $y=$ akım derinliği; $t=$ zaman; $I_{E}=$ enerji çizgisi eğimi; $I_{0}=$ kanal taban eğimi ve $g=$ yerçekim ivmesini ifade etmektedir.

Temel denklemlerin yanı sıra baraj yıkılması ile ilgili bazı yaklaşımlara da ihtiyaç vardır. Baraj yıkılması esnasında gerçekleşen gedik gelişiminin simülasyonunun oluşturulması ve oluşan çıkış hidrografının bulunabilmesi için, gediğin son geometrisinin ve yıkılma oranı gibi parametrelerin 
belirlenmesi gerekmektedir. Gediğin baraj eksenindeki konumunun, nihai taban genişliğinin, şev eğimlerinin, toplam oluşum süresinin, gedik oluşumunun üzerinden aşma veya borulanma gibi farklı baraj yıkılma senaryoları için başlama anının ve çıkan akımın savak veya orifis katsayısının belirlenerek HEC-RAS programında tanımlanması gerekmektedir. Baraj yıkılması sonucu baraj gövdesinde oluşacak gediğin şekli yaklaşık olarak dikdörtgen, üçgen, trapezoidal veya parabolik olarak alınabilmektedir [16]. Çalışmada HEC-RAS programında yürütülen yıkılma analizleri sonucu farklı yıkılma tiplerine bağlı olarak farklı gedik açıklıkları oluşturulmuş ve bu şekilde farklı yıkılma senaryoları elde edilmiştir.

Baraj yıkılmasında önemli olan bir diğer parameter ise yıkılma süresi olup gedik oluşumunun başlangıcından, açıklığın ulaşacağı son büyüklüğe kadar devam eden zaman olarak tanımlanmaktadır. Yıkılma süreleri en çok barajın büyüklügüne, kullanılan gövde malzemesine ve dolgunun yapısal dayanımına bağlıdır [20]. Bu çalışmada Rahmanlar Barajı'nın yıkılma analizi için programda başlangıç ve bitiş süreleri ile otuz saniyelik hesap adım aralığı tanımlanmıştır. Özellikle dar vadilerde yapılan analizlerde hesap adım aralığı stabiliteyi etkileyen Courant sayısı ile belirlenmektedir. Fakat arazi koşullarının Rahmanlar Barajı'ndaki gibi yayvan olması durumunda Courant sayısı stabilite üzerinde direkt etkili olmamaktadır. Courant sayısına göre hesap adımı belirlenmesi durumunda ise model simülasyon süresi çok uzun olmakta ve model sonucunda gereksiz büyük dosyalar elde edilmektedir. Bu sebeple Baraj Yıkılması Modellerinde, HEC-Hydrologic Engineering Center yayınlarında da belirtildiği üzere Courant sayısından bağımsız olarak stabilite sağlanması koşuluyla hesap adım aralığı 1 saniye - 60 saniye aralığında seçilebilmektedir. Bu nedenle çalışmada bu değerlerin ortalaması olan 30 saniye kullanılmış ve stabilitenin de sağlandığ tespit edilmiştir.

Gedik genişleme oranı ise derinlik ve genişlikteki büyüme, yıkılma oranı olup, söz konusu büyüme oranı doğrusal veya doğrusal olmayan bir değişim gösterebilmektedir. Yıkılma büyüme oranı $\mathrm{p}$ olan gediğin mevcut taban seviyesi $\left(h_{b t}\right)$ olarak alındığında $0<t_{b}<t$ için Eş. 2.3'e göre hesaplanmaktadır [21].

$$
\mathrm{h}_{\mathrm{bt}}=\mathrm{h}_{\mathrm{d}}-\left(\mathrm{h}_{\mathrm{d}}-\mathrm{h}_{\mathrm{bm}}\right) \frac{\mathrm{t}_{\mathrm{b}}}{\mathrm{t}} \mathrm{p}
$$

Burada $h_{b t}=t_{b}$ anında gediğin taban seviyesi; $h_{d}=$ barajın taban seviyesi; $t=$ gedik oluşum süresi; $t_{b}=b$ gedik taban genişliğinin oluşması için geçen süre; $h_{b m}=t$ anında en düşük gedik taban seviyesi ve $p=$ yıkılma oranıdır $(1<p<4)$. Ayrıca, gedik taban genişliği $b$ ile gedik oluşum oranı $\mathrm{p}$ arasında Eş. 2.4 'te verilen ilişki bulunmaktadır.

$$
\mathrm{B}_{\mathrm{t}}=\mathrm{b}_{\mathrm{m}} \frac{\mathrm{t}_{\mathrm{b}}}{\mathrm{t}} \mathrm{p}
$$

Burada $B_{t}=t_{b}$ anında gedik taban genişliği ve $b_{m}=t$ anında maksimum gedik taban genişliğidir. Ortalama gedik genişliği, gedik şev eğimleri ile gedik oluşum süresi gibi parametreler ise literatürde farklı ampirik bağıntılar kullanılarak hesaplanabilmektedir. Çalışmada Froehlich ampirik bağıntıları kullanılmıştır [22]. Rahmanlar Barajı'nın talvegden olan yüksekliği 76 m olduğundan Froehlich yaklaşımına göre maksimum gedik yüksekliği $H_{b} 70 \mathrm{~m}$ olarak seçilmiş̧ir. $H_{w}$ ise gedik tabanının su seviyesine olan yüksekliği olup 66,40 m'dir. Ortalama gedik genişliği $B_{o r t}$ ve gedik oluşum süresi $t_{f}$ Froehlich formüllerine göre bulunmuştur. Gedik taban genişliği $B_{b}$ ise geometriden hesaplanmıştır. Çalışmada suyun barajın üzerinden aşma durumunu içeren senaryoda şev eğimi 1:1 ve borulanma olması durumunu içeren dört senaryoda ise şev eğimi $0,7-1,0$ aralığında alınmıştır.

Amerika Birleşik Devletleri Colorado Eyaletinde Su Kaynakları İdaresi'nin Baraj Güvenliği Dairesince 2010 yılında hazırlanan "Guidelines For Dam Breach Analysis" adlı dokümanında yer alan baraj gedik parametrelerini hesaplayan farklı birçok amprik denklem önerilmiş olup ilgili gedik değişkenleri Şekil 1'de verilmiştir [23]. Bu rehberde ayrıca tahmin hesaplarını doğrulayan birkaç genel kriter de yer almaktadır. Bu kontrol kriterlerinin başlıcaları arasında aşağıdaki iki kriter çalışma kapsamında da kullanılmıştır.

1. Ortalama gedik genişliğinin gedik yüksekliğine oranının 0,6 ' dan küçük olması halinde kullanılan gedik oluşum eşitliği şüpheli veya rezervuar yalnızca borulanma gerçekleştirecek kadar küçük demektir. 
2. Ortalama gedik genişliğinin, gedik oluşum süresine oranı olarak ifade edilen aşınma oranının (ER) kabul edilebilirliğinin kontrolü için aşınma oranının gedik tabanı ile su seviyesi arasındaki yüksekliğe oranı kontrol edilmelidir. Bulunan bu oran $1,6<\left(\mathrm{ER} / \mathrm{H}_{\mathrm{b}}\right)<21$ aralığında olmalıdır.

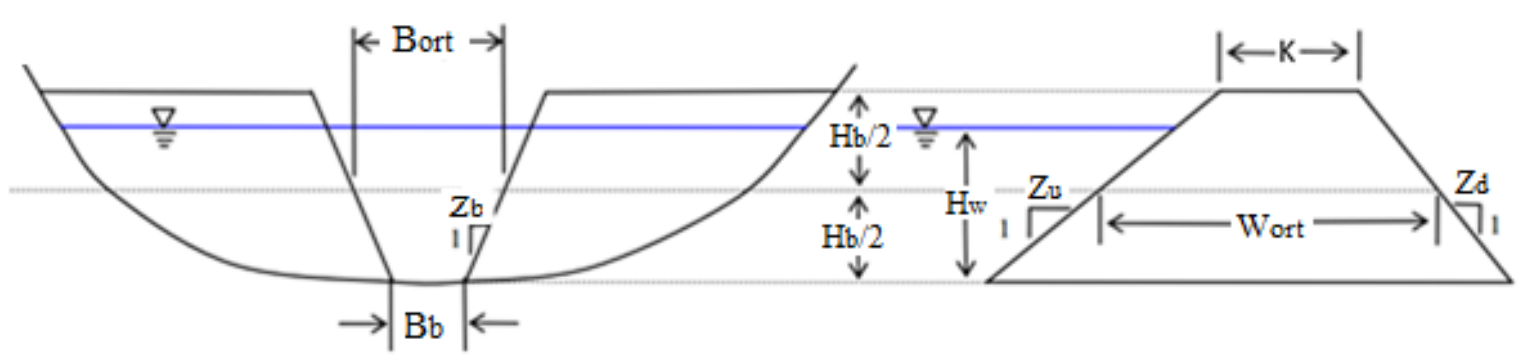

Şekil 1. Gedik değişkenleri [23]

Bu çalışmada Eş. 2.5 ve 2.6'da verilen Froehlich ampirik bağıntıları seçilerek hesaplanan tahmini gedik parametreleri, HEC-RAS programında tanımlanarak farklı yıkılma senaryolar ile çalışılmıştır. Burada Froehlich yaklaşımının seçilmesinin nedeni HEC-RAS programında gedik şev eğimlerinin de değiştirilmesi suretiyle farklı senaryoların çalışılma imkanının olmasıdır. Suyun barajın üzerinden aşması sonucunda barajın yıkılma durumunda bir tane ve borulanma nedeniyle yıkılma durumunda dört tane olmak üzere oluşturulan toplamda beş farklı yıkılma senaryosu ile çalışılmıştır.

$$
\mathrm{B}_{\text {ort }}=8,239 \mathrm{~K}_{0} \mathrm{~V}_{\mathrm{w}}^{0,32} \mathrm{H}_{\mathrm{b}}^{0,04}
$$

Burada Bort ortalama gedik genişliği olup borulanma olması durumunda $\mathrm{K}_{0}=1,0$, suyun barajın üzerinden aşması durumunda ise $\mathrm{K}_{0}=1,3$ alınmaktadır. Gedik şev eğimleri ise borulanma için $Z_{b}(Y: D)=0,7: 1$, suyun barajın üzerinden aşması durumu için ise $Z_{b}(Y: D)=1: 1$ olarak alınmaktadır. Froehlich yaklaşımına göre gedik oluşum süresi $t_{f}$ ise Eş. 2.6' da verilmiştir [22].

$$
\mathrm{T}_{\mathrm{f}}=3,664 \sqrt{\frac{\mathrm{V}_{\mathrm{w}}}{\mathrm{gHb}^{2}}}
$$

Tablo 1'de farklı baraj tipleri için kullanılan gedik parametreleri görülmektedir.

Tablo 1. Baraj yıkılmasında kullanılan gedik parametreleri [24]

\begin{tabular}{|l|c|l|}
\hline Gedik Parametreleri & Değerleri & \multicolumn{1}{|c|}{ Baraj Tipi } \\
\hline \multirow{2}{*}{$\begin{array}{l}\text { Ortalama } \\
\text { genişliği }\left(\mathrm{B}_{\text {ort }}\right)\end{array}$} & $0,5 H_{d}<B_{\text {ort }}<3 H_{d}$ & Toprak, kaya dolgu \\
\cline { 2 - 3 } & $B_{\text {ort }=0,8^{*} \text { kret uzunluğu }}$ & Cüruf, zayiat dolgu \\
\cline { 2 - 3 } & $B_{\text {ort }}=$ kret uzunluğu & Beton, kemer \\
\hline \multirow{3}{*}{$\begin{array}{l}\text { Gedik şev eğimleri } \\
(1: Z)\end{array}$} & $0<\mathrm{Z}<2$ & Hepsi \\
\cline { 2 - 3 } & $0,25<\mathrm{Z}<2$ & Yı̆ğma, ağırlık \\
\cline { 2 - 3 } & $1<\mathrm{Z}<2$ & Cüruf, zayiat dolgu \\
\hline \multirow{3}{*}{$\begin{array}{l}\text { Y1k1lma süresi } \\
\text { (saat) }\end{array}$} & $0,1<t_{f}<3,0$ & Hepsi \\
\cline { 2 - 3 } & $0,1<t_{f}<0,3$ & Yı̆̆ma, ağırlık, cüruf, zayiat dolgu \\
\cline { 2 - 3 } & $0,1<t_{f}<0,5$ & Dolgu, tasarlanmamış, zayıf inşa edilmiş \\
\cline { 2 - 3 } & $0,3<t_{f}<3,0$ & Dolgu,tasarlanmış, sıkıştırılmış \\
\hline
\end{tabular}

3. RAHMANLAR BARAJI UYGULAMASI (APPLICATION TO RAHMANLAR DAM)

3.1. Pilot Bölge ve Mevcut Baraj Bilgileri (Information about Pilot Area and Existing Dam) 
Proje alanı, Türkiye'nin batısında, İzmir İli'nin 120 km güneydoğusundaki Ödemiş İlçesi'nin yaklaşık 6 km kuzeybatısında yer alan Üzümlü köyünün doğusunda akan Rahmanlar Deresi üzerinde bulunmaktadır (Şekil 2). Rahmanlar Barajı Ege Bölgesi'nde İzmir İli sınırları içinde yer alan Küçük Menderes nehrinin su potansiyelinin değerlendirilerek ekonomiye kazandırılması amaciyla 2001 yılında planlama çalışmaları tamamlanarak DSİ Genel Müdürlüğü Etüt ve Planlama Dairesi Başkanlığı tarafından tasdik edilmiş olan sulama ve içme suyu temini amaçlı "Küçük Menderes Projesi" kapsamında yer almaktadır. Proje akım yönünde 110 km uzunluğundadır. Rahmanlar Baraj1 gövde tipi ön yüzü beton kaplı, dolgu bir baraj olarak tasarlanmıştır. Temelden yüksekliği 92,30 m ve talvegden yüksekliği $75 \mathrm{~m}$ olan gövde, kum çakıl malzemeden ve mansabında kaya dolgu zonundan oluşmaktadır. Gövdede geçirimsizlik memba yüzündeki beton kaplama ile sağlanmaktadır. Beton kaplama altındaki iki adet filtre zonuna ek olarak kret ortasından başlayıp memba yönüne 1: 1 (yatay:düşey) eğimle inen filtre tabakası yer almaktadır.

Rahmanlar Barajı yıkılma analiz modelinde öteleme uzunluğu yaklaşık 3,5 km olup, öteleme Rahmanlar Barajı aksından başlatılarak, mansapta yer alan risk altındaki Ortaköy'e kadar devam ettirilmiştir. Barajın mansabında yer alan Ortaköy ve Üzümlü köylerinde yaşayan halkın yanı sıra, bu alanda birçok tarım arazisi de risk altında bulunmaktadır. Ortaköy'den sonra vadi genişliği arttığından taşkın su derinliğinin düşeceği, dolayısıyla Yenice köyü yerleşimi ile Ödemiş İlçesi için taşkın riskinin oluşmayacağ 1 düşünülmüştür. Tehlike altındaki bu köylerden Üzümlü 280 kişilik nüfusa sahip olup baraj aksından $1 \mathrm{~km}$ mansapta, Ortaköy ise 127 kişilik nüfusa sahip olup barajın yaklaşık 2,7 m mansabında yer almaktadır.

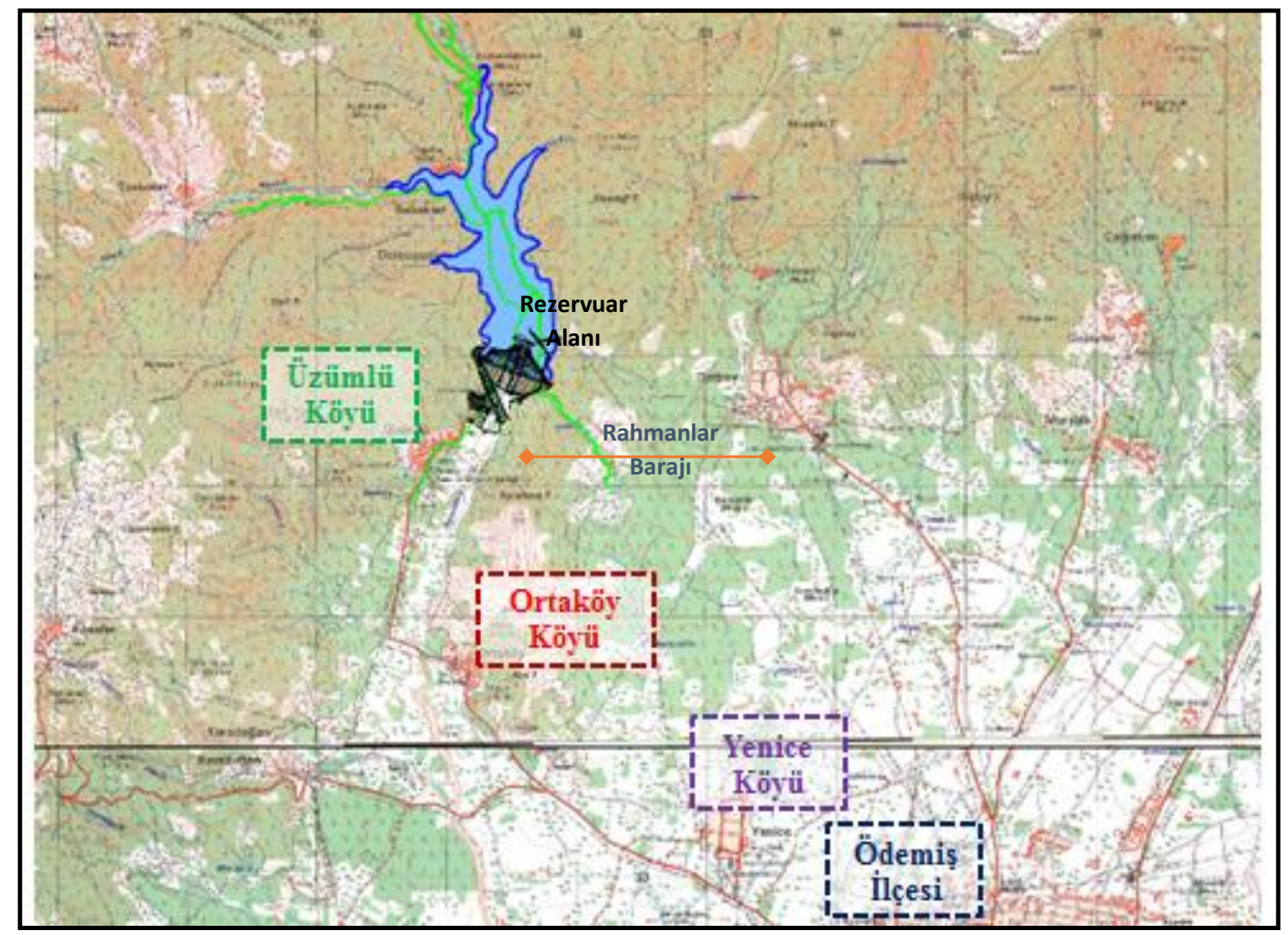

Şekil 2. Barajin rezervuar ve mansap haritası (1/25 000)

\subsection{B Sayısal Modelleme (1D Numerical Modelling)}

Su yüzü profillerinin tespit edilebilmesi için yapılan tek boyutlu hesaplamalar HEC-RAS hidrolik analiz programında gerçekleştirilmiştir. Buna göre göl alanı depolama alanı olarak oluşturularak modellenmiş ve gölde rezervuar depolama yöntemiyle öteleme yapılırken mansapta zamanla değiş̧en akım denklemleri kullanılmıştır. Bu yöntemde program göl alanı ile baraj kesitinin arasında en az iki adet kesite ihtiyaç duyulmaktadır [25]. Zamana bağlı akım ötelenmesi esnasında bu kesitlerin su 
seviyesi, göl alanının yıkılma anındaki su seviyesini temsil etmektedir. Dere yatağı boyunca akış yönüne dik olan düzlemde alınan kesitler baraj aksından başlayarak mansapta taşkın riski altında olan Ortaköy'e kadar devam ettirilmiştir. Bu çalışmada, baraj aksından alınan en kesitler Devlet Su İşleri Harita Müdürlüğü’nün hazırladığ1 1/5 000 ölçekli topoğrafik haritalar kullanılarak, barajın mansabı boyunca alınan enkesitler ise Harita Genel Komutanlığından (HGK) alınan 1/25 000 ölçekli sayısal haritalar kullanılarak hazırlanmıştır. Dere güzergâhından alınan en kesitler sabit aralıklarla yerleştirilmiş ve numaralandırma mansaptan membaya doğru artan şekildedir. Bu sebeple Rahmanlar Deresi üzerinden alınan en kesitler barajın membainda $3370 \mathrm{~m}$ ve mansabında 0 olarak adlandırılmıştır. Bir boyutlu baraj yıkılma simülasyonları yapılırken farklı Manning pürüzlülük değerleri için elde edilen su yüzü profilleri değerlendirildiğinde, taşkın haritasını etkileyebilecek farkların oluşmadığı görülmüştür. Bu nedenle hesaplarda tabanı oldukça düzenli, sahilleri düz ve sağlam, hiç bitki örtüsü olmayan yataklar için kullanılan 0,03 değeri kullanılmıştır [26].

Dolgu barajlarda gerçekleşen yıkılma süresi 6 dakikadan 3 saate kadar farklılık gösterebilmektedir. Yıkılma süreleri en çok barajın büyüklüğüne, kullanılan gövde malzemesine ve dolgunun yapısal dayanımına bağlıdır [20]. Bu nedenlerle çalışmada Rahmanlar Barajı yıkılma analizi için program kurulumunda başlangıç ve bitiş süreleri ile otuz saniyelik hesap adım aralığıyla 1 Eylül 2014 saat 24:00'de başlayan simülasyon 6 Eylül 2014 saat 03:00'da sonlandırılmıştır. Baraj gövdesinde gediğin oluşumunun ise 3 Eylül tarihinde saat 06:00'da başladığ 1 kabul edilmiştir.

Dere yatağ 1 modellenirken taşkın öteleme için memba ve mansap sınır koşullarının da programda tanıtılması gerekmektedir. HEC-RAS programında dinamik akım koşullarında su yüzü profilleri hesaplanırken Şekil 3'te verilen katastrofik taşkın hidrografı memba sınır koşulu olarak programa girilmiştir. Mansap sınır koşulu olarak, mansap kesitinin olduğu noktada normal akım derinliğine karşılık gelen taban eğimi okunarak programda tanımlanmıştır. Zamana bağlı akımın rezervuarda ötelenmesi, basit bir yöntem olan Level-Pool Öteleme yöntemi ile gerçekleştirilmiştir. Uzun olmayan ve giriş hidrografı zamana bağlı olarak hızlı bir şekilde değişmeyen rezervuarlarda uygulanabilir olan bu basit yönteme Rezervuar Depolama Ötelemesi de denmektedir [21]. Bu yöntemde, su yüzünün rezervuarın genişliği boyunca aynı seviyede olduğu varsayılmaktadır.

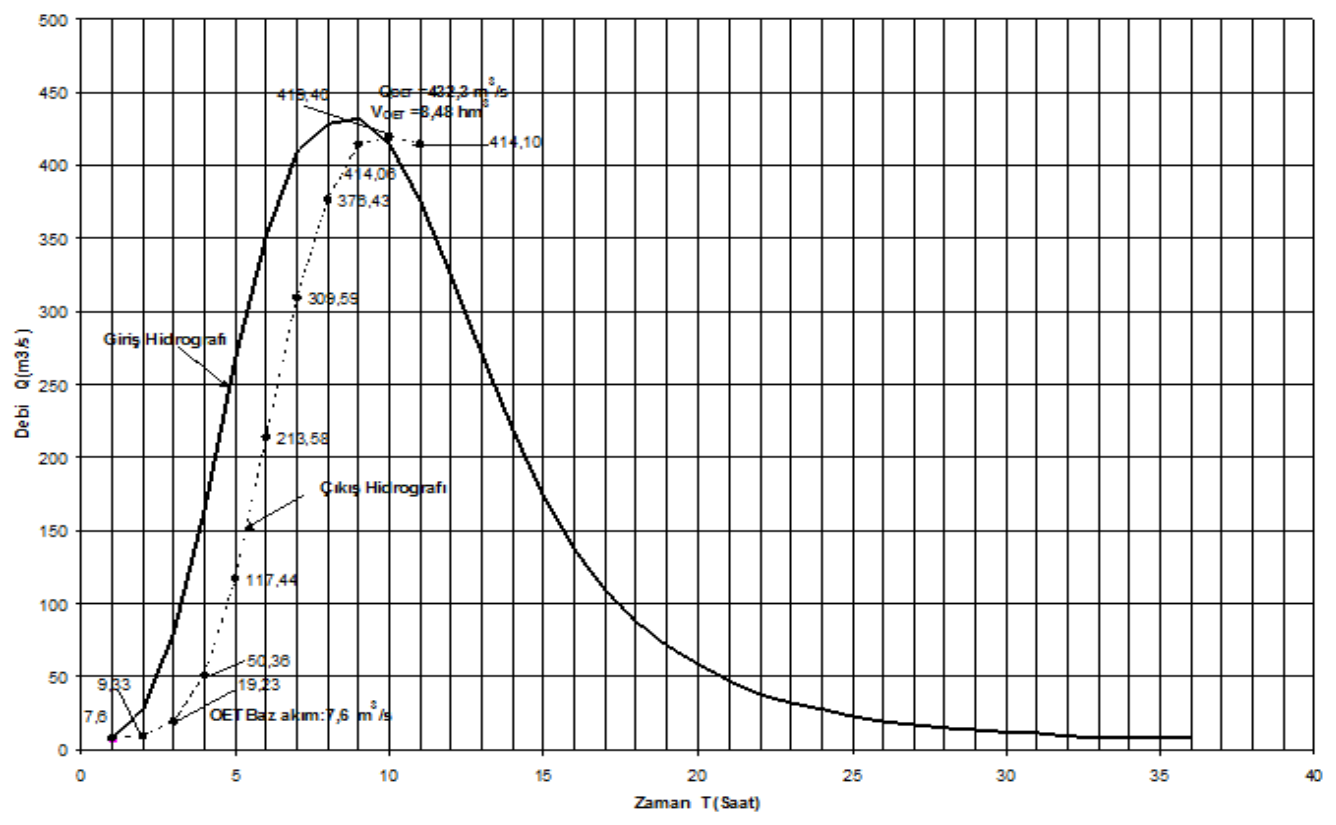

Şekil 3. Rahmanlar Barajı olası en büyük taşkın debisinin hidrografi [18]

\section{BULGULAR VE TARTIŞMA (RESULTS AND DISCUSSION)}

Tablo 2'de çalışmada belirlenmiş baraj yıkılma senaryoları, elde edilen sonuçlar ile bunların değerlendirilmeleri görülmektedir. Çalışmada HEC-RAS yazılımıyla gerçekleştirilen simülasyonlarda her kesitteki maksimum su seviyesi, çıkış debisi, çıkış hidrografı, maksimum akım 
ve maksimum su seviyesinin gerçekleştiği zamanlar belirlenmiştir. Gövdede oluşan gedikten çıkan suyun kesitlerde oluşturduğu maksimum derinlikler tüm senaryolar için ayrı ayrı bulunmuştur [18].

\subsubsection{HEC-RAS baraj yıkılma sonuçlarının değerlendirilmesi}

Şekil 4'te HEC-RAS programında suyun barajın üzerinden aşması, Şekil 5'te ise borulanma durumunda baraj gövdesinde yıkılmanın gelişmesi görülmektedir.
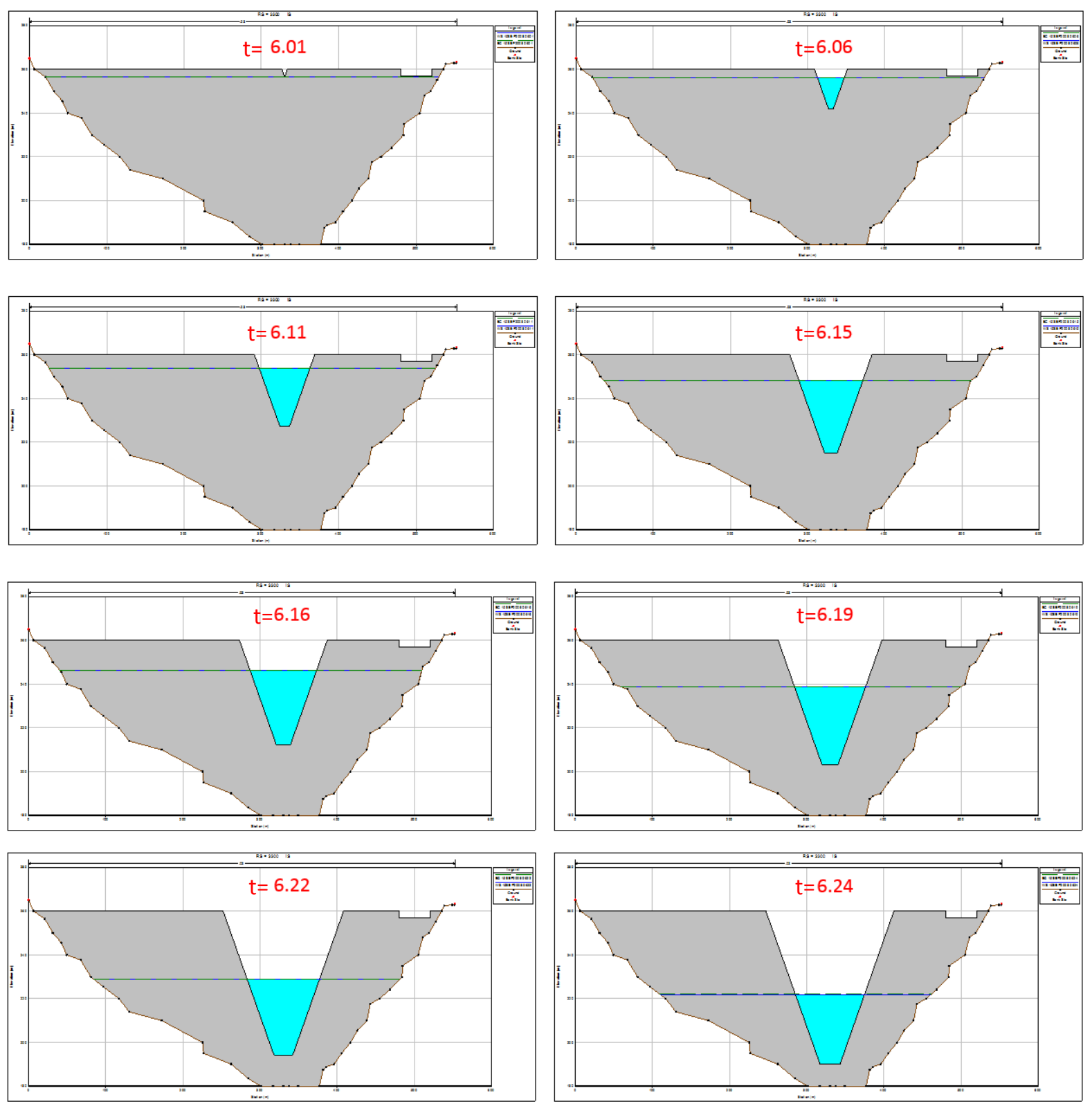

Şekil 4. HEC-RAS programında suyun barajın üzerinden aşmasıyla yıkılmanın geliş̧imi 
Tablo 2. [22] yöntemine göre belirlenen ylkulma senaryoları [18]

\begin{tabular}{|c|c|c|c|c|c|c|c|c|c|c|}
\hline \multirow{3}{*}{$\begin{array}{c}\text { Parametre } \\
\qquad H_{w}(\mathrm{~m})\end{array}$} & \multicolumn{2}{|c|}{ Senaryo No.1 } & \multicolumn{2}{|c|}{ Senaryo No.2 } & \multicolumn{2}{|c|}{ Senaryo No.3 } & \multicolumn{2}{|c|}{ Senaryo No.4 } & \multicolumn{2}{|c|}{ Senaryo No.5 } \\
\hline & \multicolumn{2}{|c|}{ Üzerinden aşma } & \multicolumn{2}{|c|}{ Borulanma } & \multicolumn{2}{|c|}{ Borulanma } & \multicolumn{2}{|c|}{ Borulanma } & \multicolumn{2}{|c|}{ Borulanma } \\
\hline & $66,40 \mathrm{~m}$ & & 66,40 & & 66,40 & & 66,40 & & 66,40 & \\
\hline$V_{w}\left(\mathrm{hm}^{3}\right)$ & 24,00 & & 24,00 & & 24,00 & & 24,00 & & 24,00 & \\
\hline$A_{s}\left(\mathrm{~km}^{2}\right)$ & 0,84 & & 0,84 & & 0,84 & & 0,84 & & 0,84 & \\
\hline$K(\mathrm{~m})$ & 12,00 & & 12,00 & & 12,00 & & 12,00 & & 12,00 & \\
\hline$H_{b}(\mathrm{~m})$ & 70,00 & & 70,00 & & 70,00 & & 70,00 & & 70,00 & \\
\hline$Z_{u}$ & 1,8 & $Z(Y): 1(D)$ & 1,8 & $Z(Y): 1(D)$ & 1,8 & $Z(Y): 1(D)$ & 1,8 & $Z(Y): 1(D)$ & 1,8 & $Z(Y): 1(D)$ \\
\hline$Z_{d}$ & 1,8 & $Z(Y): 1(D)$ & 1,8 & $Z(Y): 1(D)$ & 1,8 & $Z(Y): 1(D)$ & 1,8 & $Z(Y): 1(D)$ & 1,8 & $Z(Y): 1(D)$ \\
\hline$Z_{b}$ & 1 & $Z(Y): 1(D)$ & 0,7 & $Z(Y): 1(D)$ & 0,8 & $Z(Y): 1(D)$ & 0,9 & $Z(Y): 1(D)$ & 1 & $Z(Y): 1(D)$ \\
\hline$t_{f}$ & 0,39 & & 0,39 & & 0,39 & & 0,39 & & 0,39 & \\
\hline$B_{\text {ort }}(\mathrm{m})$ & 95,68 & & 73,58 & & 73,58 & & 73,58 & & 73,58 & \\
\hline$B_{b}(\mathrm{~m})$ & 25,66 & & 24,60 & & 17,59 & & 10,61 & & 3,60 & \\
\hline & & & & Sor & çların kc & atrolü & & & & \\
\hline$B_{\text {ort }} / H_{b}=$ & 1,37 & $>0,6$ & 1,05 & $>0,6$ & 1,05 & $>0,6$ & 1,05 & $>0,6$ & 1,05 & $>0,6$ \\
\hline$E R\left(B_{\text {ort }} / t_{f}\right)=$ & 245,32 & & 188,66 & & 188,66 & & 188,66 & & 188,66 & \\
\hline$E R / H_{b}=$ & 3,50 & $1,6<E R / H_{b}<21$ & 2,70 & $1,6<E R / H_{b}<21$ & 2,70 & $1,6<E R / H_{b}<21$ & 2,70 & $1,6<E R / H_{b}<21$ & 2,70 & $1,6<E R / H_{b}<21$ \\
\hline
\end{tabular}

Tabloda $H_{w}=$ gediğin tabanından barajdaki su seviyesine olan yükseklik $(\mathrm{m}) ; H_{b}=$ gedik yüksekliği $(\mathrm{m}) ; \mathrm{t}_{f}=$ baraj yıkılma süresi (saat); $Z_{u}=$ barajın memba yüzü şev eğimi $Z(Y): 1(D) ; Z_{d}=$ barajın mansap yüzü şev eğimi $Z(Y): 1(D) ; Z_{b}=$ gedik şev eğimi $Z(Y): 1(D) ; B_{b}=$ gediğin taban genişliği $(\mathrm{m}) ; B_{o r t}=$ gedik ortalama genişliği (m); $E R=$ aşınma oranı; $K=$ kret genişliği (m); $A_{s}=$ rezervuar yüzey alanı $\left(\mathrm{m}^{2}\right)$ ve $V_{w}=$ yıkılma anında rezervuardaki su hacmidir $\left(\mathrm{m}^{3}\right)$. 


\section{Senaryo 1 için analiz sonuçları}

Rezervuardaki suyun 06:00 anında barajın üzerinden aşması ile gerçekleşen yıkılma analizi sonucunda, baraj mansabındaki kesitlerde maksimum derinlikler Ortaköy ve Üzümlü köyleri için ayrı ayrı belirlenmiştir. Buna göre Üzümlü köyünde maksimum su derinliğinin yıkılma anından sonra 22. dakikada, Ortaköy'de ise 23. dakikada meydana geldiği görülmüştür. Şekil 6'da Senaryo 1'de yıkılmadan 23 dakika sonraki su yüzü profili görülmektedir.
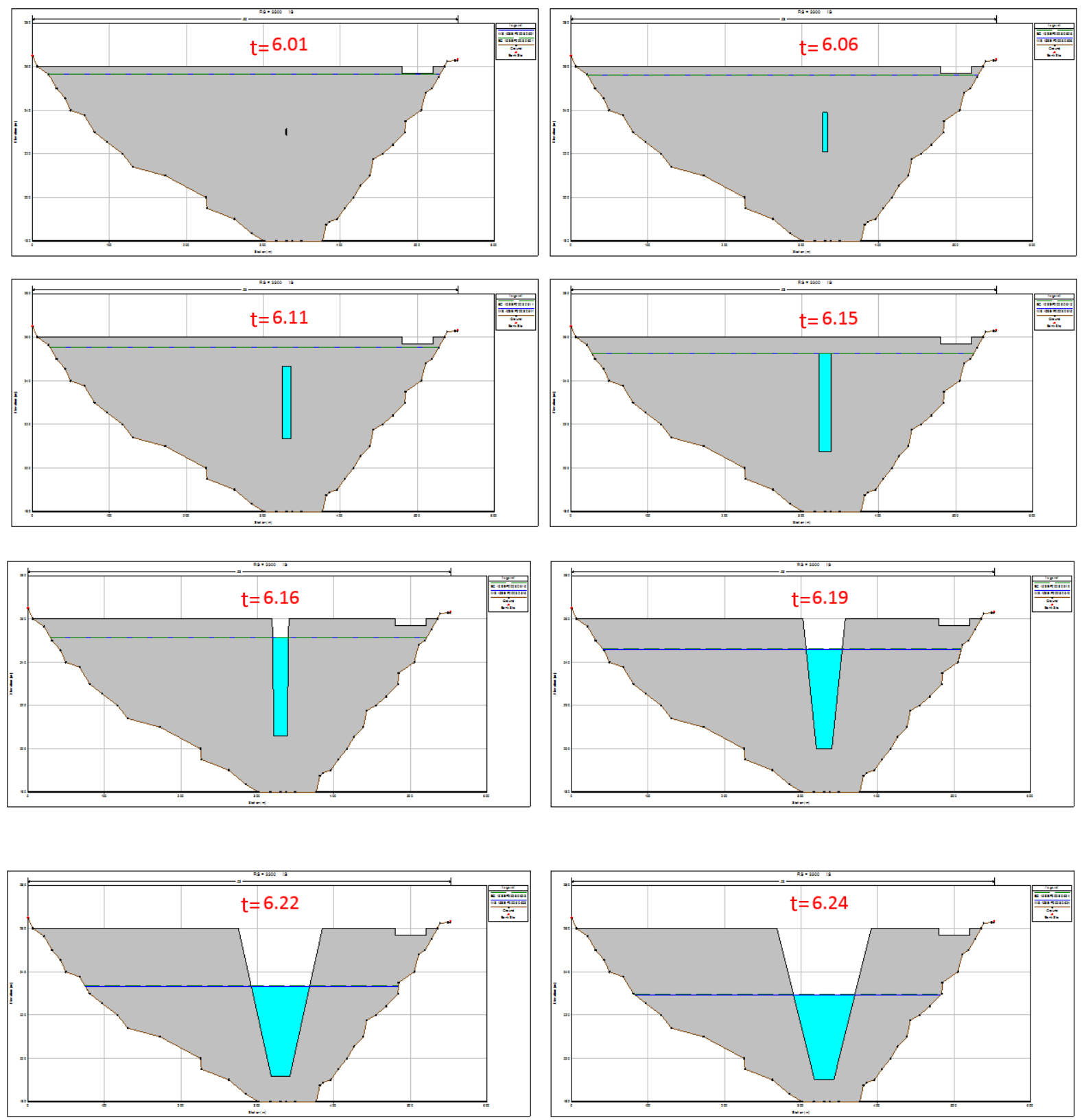

Şekil 5. HEC-RAS programında borulanma durumunda yıkılmanın gelişimi

Senaryo 2 için analiz sonuçları

Senaryo 2'de 06:00 anında borulanma ile gerçekleşen yıkılma analizinin sonuçları, baraj mansabındaki Üzümlü ve Ortaköy köylerinde maksimum derinliğin yıkılmadan sonra 23. ve 24. dakikalarda oluştuğunu göstermektedir. 


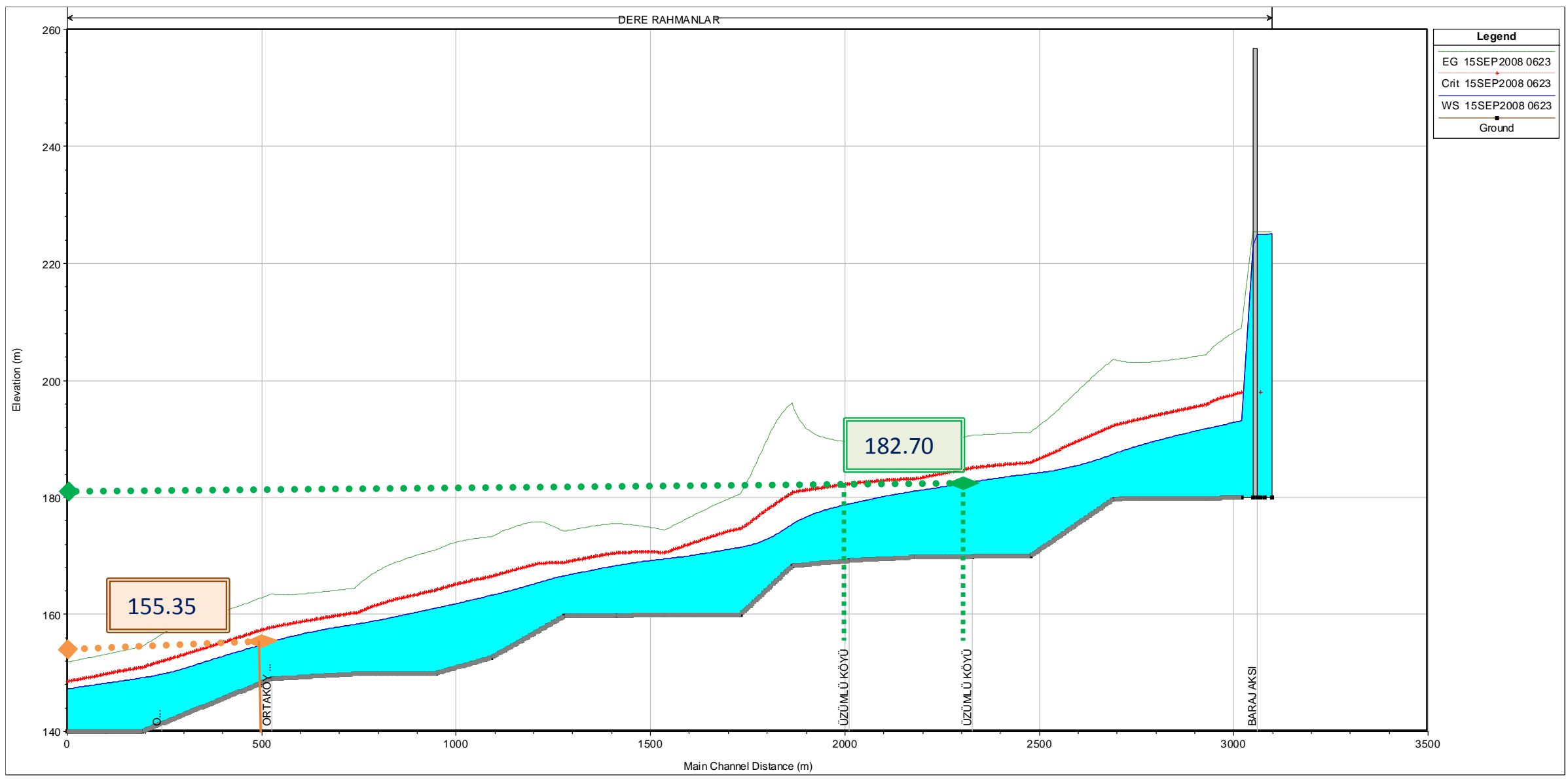

Şekil 6. Senaryo 1'e göre yıkılmanın ardından 06:23 anında gerçekleşen maksimum su yüzü profili 


\section{Senaryo 3 için analiz sonuçları}

Senaryo 3'te 06:00 anında borulanma ile gerçekleşen yıkılma analizinin sonuçları, baraj mansabındaki Üzümlü ve Ortaköy köylerinde maksimum derinliğin yıkılmadan sonra 24. ve 25. dakikalarda oluştuğunu göstermektedir.

\section{Senaryo 4 için analiz sonuçları}

Senaryo 4'te saat 06:00 anında borulanma ile gerçekleşen yıkılma analizinin sonuçları, baraj mansabındaki Ortaköy ve Üzümlü köylerinde maksimum derinliğin yıkılmadan sonra 24. ve 25. dakikalarda oluştuğunu göstermektedir.

\section{Senaryo 5 için analiz sonuçları}

Senaryo 5'te saat 06:00 anında borulanma ile gerçekleşen yıkılma analizinin sonuçları, baraj mansabındaki Ortaköy ve Üzümlü köylerinde maksimum derinliğin yıkılmadan sonra 24. ve 25. dakikalarda oluştuğunu göstermektedir.

Tablo 3 ve Tablo 4'te farklı yıkılma senaryoları için barajın mansabında yer alan Ortaköy ve Üzümlü köylerinde elde edilen maksimum su seviyeleri ile mansapta ötelenen pik debinin büyüklükleri verilmiştir. Tablo 3'te görülen sonuçlarda beklenildiği üzere, baraj gövdesinde oluşan gedikten çıkan taşkın debisinin ötelenmesi sonucunda en mansaptaki kesitten çıkan taşkın pik değerinin küçüldügü görülmüştür.

Tablo 3. 1B analizler sonucu köylerde oluşan su kotları [18]

\begin{tabular}{|c|c|c|}
\hline Senaryo No & Üzümlü Köyü & Ortaköy Köyü \\
\hline Senaryo 1 & $182,7 \mathrm{~m}$ & $155,4 \mathrm{~m}$ \\
\hline Senaryo 2 & $183,3 \mathrm{~m}$ & $155,4 \mathrm{~m}$ \\
\hline Senaryo 3 & $183,6 \mathrm{~m}$ & $155,8 \mathrm{~m}$ \\
\hline Senaryo 4 & $183,9 \mathrm{~m}$ & $156,0 \mathrm{~m}$ \\
\hline Senaryo 5 & $184,5 \mathrm{~m}$ & $156,2 \mathrm{~m}$ \\
\hline
\end{tabular}

Tablo 4. Baraj aksında ve mansapta oluşan pik debiler ve oluşma zamanları [18]

\begin{tabular}{|c|c|c|c|}
\hline Senaryo No & $\begin{array}{c}\mathrm{Q}\left(\mathrm{m}^{3} / \mathrm{s}\right) \\
\text { baraj aks1 }\end{array}$ & $\begin{array}{c}\mathrm{Q}\left(\mathrm{m}^{3} / \mathrm{s}\right) \\
\text { mansap kesiti }\end{array}$ & $\begin{array}{c}\text { Pik debinin } \\
\text { oluşma zamanı (saat:dk) }\end{array}$ \\
\hline Senaryo 1 & 25816,32 & 25386,93 & $06: 25$ \\
\hline Senaryo 2 & 30202,86 & 29675,24 & $06: 24$ \\
\hline Senaryo 3 & 32034,63 & 29950,61 & $06: 25$ \\
\hline Senaryo 4 & 34335,05 & 31286,46 & $06: 26$ \\
\hline Senaryo 5 & 38799,90 & 33842,39 & $06: 26$ \\
\hline
\end{tabular}

Şekil 7'de Senaryo 1 yıkılma senaryosu sonucunda dere yatağ 1 üzerinde oluşan su yüzü profillerinin zamanla değişimi görülmektedir. Burada yıkılma öncesi (saat 06:15 anında-rezervuar dolu durumdayken) ve yıkılma sonrası farklı zamanlarda, mansap boyunca su yüzü profilleri çizilerek dalga hareketinin oluşumu gözlemlenmiştir (Şekil 7). Böylece baraj yıkılması sonucu oluşan taşkının mansapta hangi zamanda hangi su yüksekliğine neden olacağı grafikler yardımıyla belirlenebilmiştir. 
HEC-RAS yazılımı kullanılarak Rahmanlar Barajı'nın farklı senaryolar altında yıkılması sonucu oluşan taşkın hidrografları hesaplanmış ve çıkan hidrograflar barajın mansabında yaklaşı 3,5 km'lik mesafe boyunca ötelendiği tespit edilmiştir. Şekil 7 ve Şekil 8'de verilen grafiklerde Senaryo 1'e göre barajın yıkılması sonucu, baraj aksında (km: 3300) elde edilen taşkın hidrografı ile öteleme mesafesinin sonundaki kesitten (km: 290) çıkan akım hidrografları görülmektedir. Diğer kesitlere ait hidrograflar ise bu iki eğrinin arasında yer almaktadır. Şekiller incelendiğinde hidrografların zamana göre bir miktar ötelenerek (=5 dakika) pik debi değerinin düştüğü ve hidrograf eğrisinin de çok az yayvanlaşma olduğu görülmektedir.

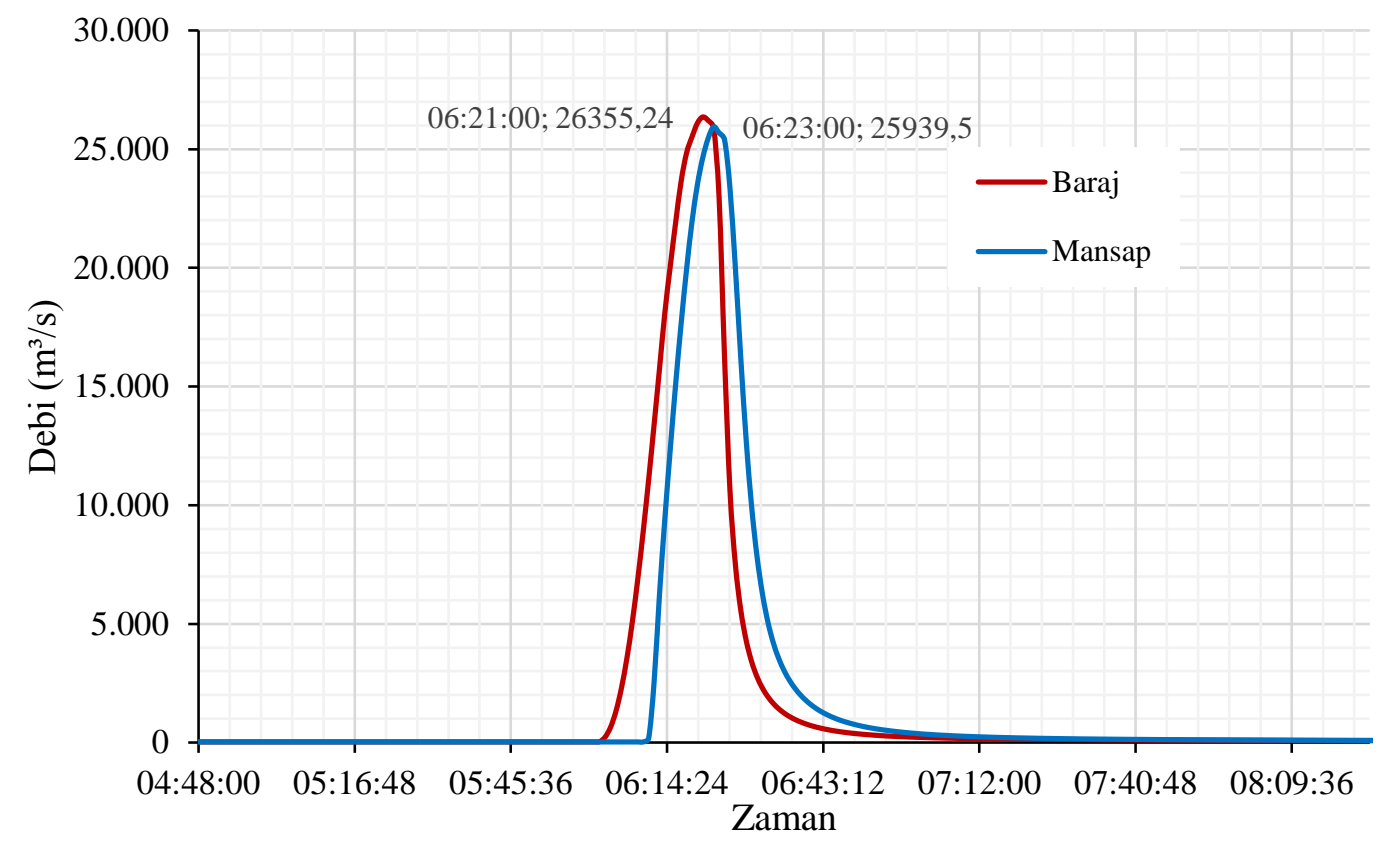

Şekil 7. Baraj aksında (km: 3300) ve mansap kesitinde(km:290) taşkın hidrografi [18]

Şekil 8'de, Senaryo-1 sonucunda dere yatağı üzerinde oluşan su yüzü profillerinin zamanla değişimi görülmektedir. Burada yıkılma öncesi (06:15 anında-rezervuar dolu durumdayken) ve yıkılma sonrası farklı zamanlarda, mansap boyunca su yüzü profilleri çizilerek dalga hareketinin oluşumu gözlenmiştir. Baraj yıkılması sonucu oluşan taşkının mansapta hangi zamanda hangi yükseklikte olacağı bu grafikler yardımıyla belirlenmiştir.

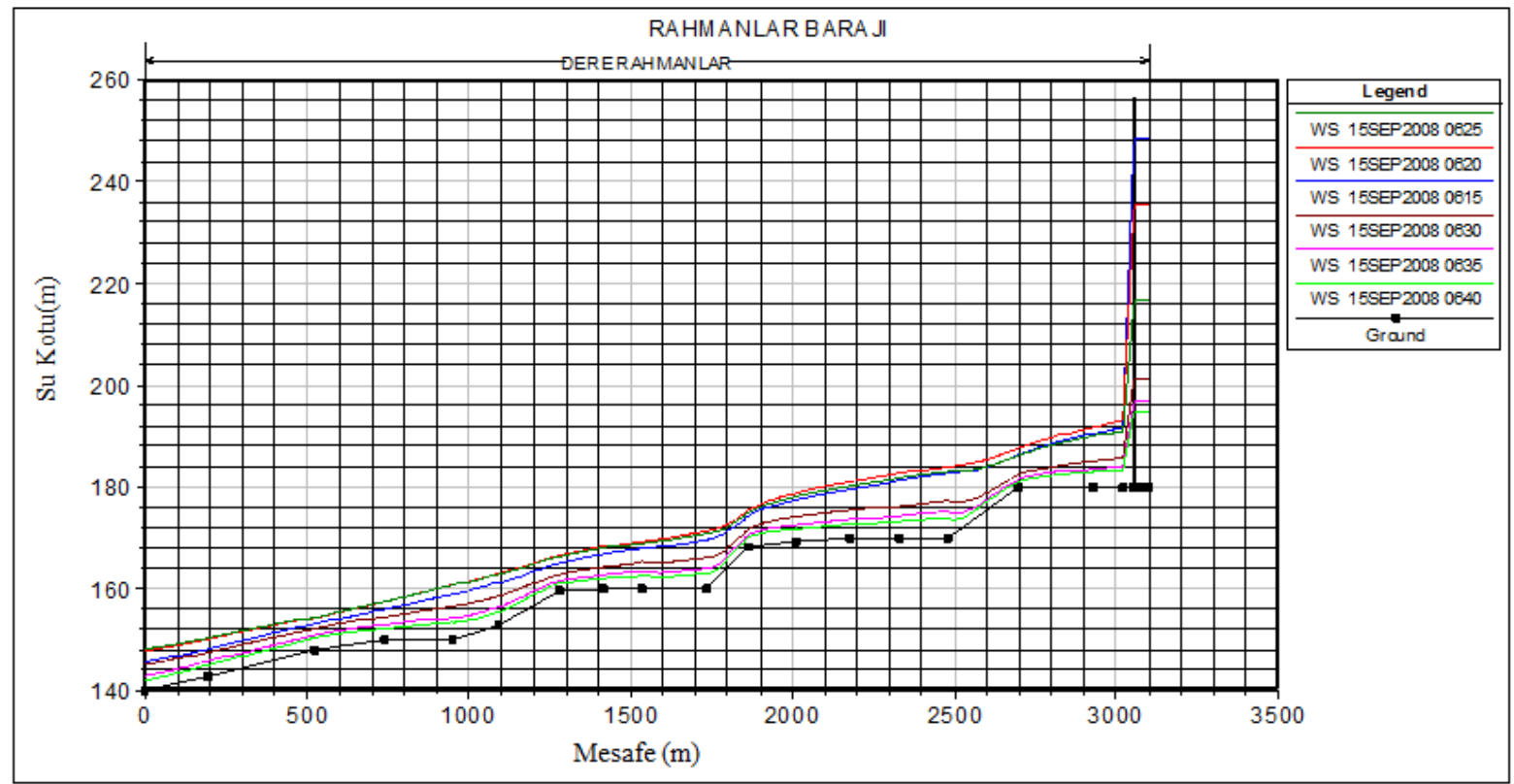

Şekil 8. Farklı zamanlardaki su yüzü profilleri [18] 


\subsubsection{Tașkın haritalarının olușturulması}

HEC-RAS programında gerçekleştirilen dinamik analizler sonucunda barajın mansabında oluşan taşkın haritası incelenmiştir. Buna göre Şekil 9'da yıkılma analizi öncesinde HEC-RAS programında gerçekleştirilen zamana bağlı akım analizi sonucunda barajın mansabında oluşan taşkın haritası, Şekil 10'da ise Senaryo 1 yıkılma analizi sonucunda mansapta oluşan taşkın haritası görülmektedir. Çalışmadaki senaryolar durumunda oluşan maksimum su yükseklikleri arasında en büyük fark yaklaşık 1 metre olarak elde edilmiştir.

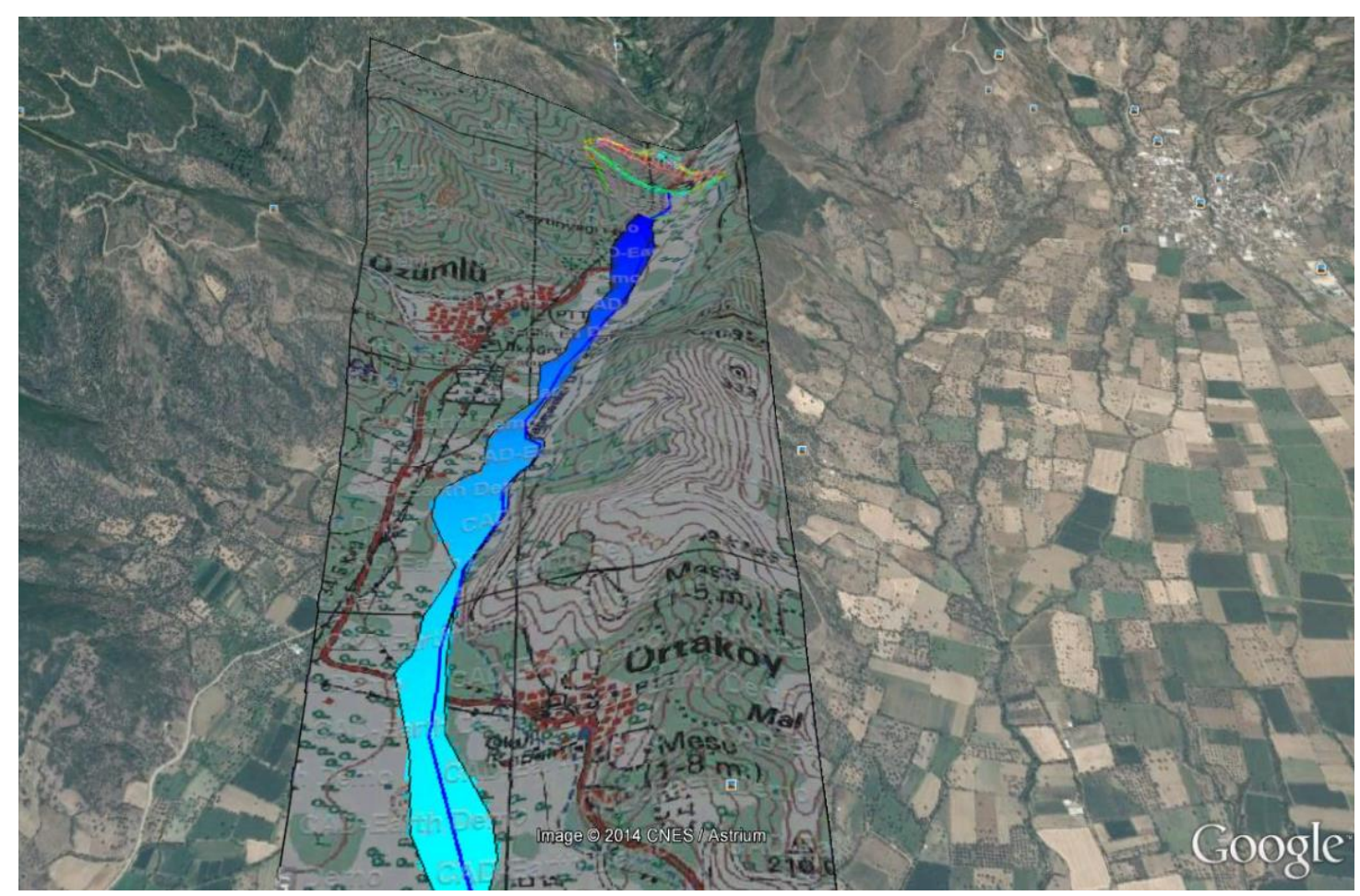

Şekil 9. Yıkılma öncesinde gerçekleştirilen dinamik taşkın analizi sonucu oluşan taşkın haritası

\section{SONUÇ (CONCLUSION)}

Çalışma kapsamında İzmir'in Ödemiş ilçesi’ndeki Rahmanlar Barajı yıkılması ve olası taşkın dalgası yayılımı modellenmesinde 1B analizler için HEC-RAS yazılımı kullanılmıştır. Analizler sonucunda Rahmanlar Barajı'nın farklı senaryolarla yıkılması sonucu oluşan taşkın hidrografları belirlenmiş ve çıkan hidrografların barajın mansabında yaklaşık $3.5 \mathrm{~km}$ mesafe ötelendiği görülmüsstür. Saint Venant eşitliğine dayanan 1B zamanla değişen analizlerde suyun tek boyutta ilerlediği varsayıldığından akım dağılımı, kesit şekli, akış yönü veya akımın diğer 2B ve 3B özelliklerindeki değişimleri modelde başarılı bir şekilde ifade edebilmek mümkün olamamaktadır. Belli aralıklarla alınan kesitlerle temsil edilen dere yatağında, akımın doğrusal bir şekilde ilerlediği varsayılmakta, ancak akımı ve araziyi gerçeklikten uzaklaştıran bu varsayımlar sayesinde analizler, 2B ve 3B analizlere kıyasla çok daha hızlı bir şekilde gerçekleştirilebilmektedir. Ücretsiz erişimi, kolay kurulumu ve kısa hesaplama süresi gibi nedenlerle Türkiye'de mevcut veya projelendirme aşamasında olan barajların mansap güvenliği ile ilgili çalışmalar yapılırken çalışmanın önem ve aciliyet durumuna göre öncelikle 1B yıkılma analizlerinin gerçekleştirilip sonuçların değerlendirilmesi, sonrasında öncelikle 2B analizlerin yapılması ve gerekli görülmesi halinde 3B analizlerin yapılması önerilmektedir. 


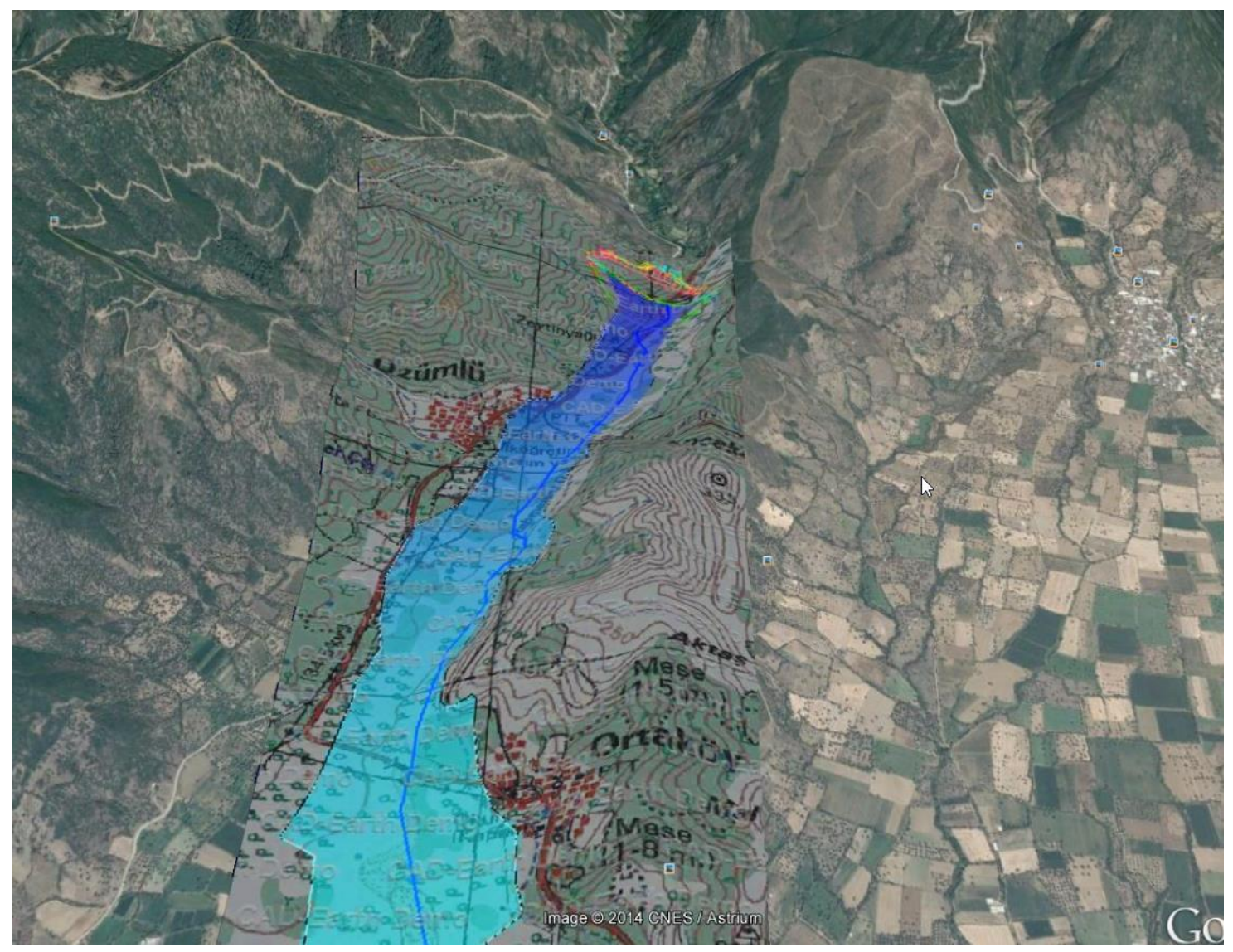

Şekil 10. Senaryo 1 yıkılma analizi sonucunda mansapta oluşan taşkın haritası

\section{KAYNAKLAR (REFERENCES)}

[1] C.V. Bellos, J.V. Soulis, and J.G. Sakkas, Experimental investigation of two-dimensional dam-break induced flows. Journal of Hydraulic Research, 30:1 (1992) 47 - 63.

[2] S.W. Bell, R.C. Elliot, and M.H. Chaudhry, Experimental results of two dimensional dam-break flows. Journal of Hydraulic Research, 30:2 (1992) 225 - 252.

[3] G. Lauber, and W.H. Hager, Experiments to dam-break wave: sloping channel. Journal of Hydraulic Research, 36:5 (1998), 761-773.

[4] B. Nsom, K. Debiane, and J.M. Piau, Bed slope effect on the dam-break problem. Journal of Hydraulic Research, 38:6 (2000) 459-464.

[5] S. Kocaman, ve H. Özmen Çağatay,Gedik Parametrelerinin Baraj Yıkılması Taşkın Dalgalarına Etkisi. Çukurova Üniversitesi, Mühendislik Mimarlık Fakültesi Dergisi, 18:1 (2003)17-34.

[6] F. Aureli, P. Mignosa, and M. Tomirotti, Experimental modelling of rapidly varying flows on wet bed and in the presence of submersible obstacles, in: Proc. River Flow, Naples, Italy, vol. 2 (2004) 849 858.

[7] S. Soares-Frazao, Experiments of dam-break wave over a triangular bottom sill. Journal of Hydraulic Research, 45:Extra Issue (2007) 19-26.

[8] H. Özmen Çağatay, and S. Kocaman, Dam-break flow in the presence of obstacle: experiment and CFD simulation. Engineering Applications of Computational Fluid Mechanics, 5:4 (2011) 541-552. 
[9] J.A.Vasquez, and J.G.B. Leal, Two-dimensional dam-break simulation over movable beds with an unstructured mesh. In Ferreira RML, Alves ECTL, Leal JGAB, Cardoso AH (eds) Riverflow 2006, vol I, Taylor \& Francis, Portugal, (2006) 1483-1491. ISBN:0-415-40815-6.

[10] R.B. Minussi, and G.F. Maciel, "Dam break-problem-complete solution and shallow water approximation comparison”, In: Altınakar MS, Kökpınar MA, Aydin I, Kirkgoz S (eds) River flow 2008, vol 1, Proceedings International conference on Fluvial Hydraulics, Izmir, Turkey, (2008) 619626 .

[11] S. Kocaman, ve H. Çağatay, "Baraj yıkılması akımının analitik ve deneysel karşılaştırılması", IV. Ulusal Su Mühendisliği Sempozyumu, Orhantepe, İstanbul, (2009) 77-87.

[12] M.S. Guney, G. Tayfur, G. Bombar, and S. Elçi, Distorted physical model to study sudden partial dam break flows in an urban area. Journal of Hydraulic Engineering, 140:11 (2014) 05014006.

[13] H. Özmen Çağatay, S. Kocaman, and H. Güzel, Investigation of dam-break flood waves in a dry channel with a hump. Journal of Hydro-environmental Research, 8 (2014), 304 - 315.

[14] FEMA P-956. Living with Dams, Know Your Risks, 2013.

[15] Z. Bozkuş, and A. Kasap, Comparison of Physical and Numerical Dam-Break Simulations. Tr. J. of Engineering and Environmental Science, 22 (1998) 429-443.

[16] Z. Bozkuş, and İ. A. Güner, Pre-Event Dam Failure Analyses for Emergency Management, Tr. J. of Engineering and Environmental Science, 25 (2001) 627-641.

[17] Z. Bozkuş, Afet Yönetimi için Baraj Yıkılma Analizleri, İMO Teknik Dergi, 15:4 (2004) 3335 - 3350.

[18] N. Palamut, Baraj Yıkılma Analizi ve Uygulaması. Yüksek Lisans Tezi, Gazi Üniversitesi, Ankara, 2014.

[19] Hydrologic Engineering Center. (HEC, 2008). HEC-RAS River Analysis System, User's Manual, Ver. 4.1, U.S. Army Corps of Engineers, Davis, California, 2008.

[20] E. Francis, and P. E. Fiegle, Embankment Dam Failure Analysis, Issues, Resolutions, and Research Needs Related to Dam Failure Analysis Workshop. Oklahoma City, Oklahoma, 2001.

[21] D.L. Fread, Breach: An Erosion Model for Earthen Dam Failures. National Weather Service, Silver Springs, Maryland,1991.

[22] D.C. Froehlich, Embankment Dam Breach Parameters and Their Uncertainties. Journal of Hydraulic Engineering, 134:12 (2008) 1708-1721.

[23] Guidelines For Dam Breach Analysis. State of Colorado Department of Natural Resources Division of Water Resources, Denver, Colorado, USA, 2010.

[24]Wahl, T. L. Prediction of Embankment Dam Breach Parameters - A Literature Review and Needs Assessment, DSO-98-004, Dam Safety Research Report, U.S. Department of the Interior, Bureau of Reclamation, Dam Safety Office, 1998.

[25] D. M. Gee, Use of Embankment Erosion Models to Estimate HEC-RAS Dam Breach Parameters, Dam Safety 2009, ASCE-EWRI, Kansas City, MO, 2009, 17-21 .

[26] V.T. Chow, Open channel Hydraulics. McGraw-Hill Book Company, New York, 1959. 